\title{
A COMPARATIVE STUDY OF METERED DOSE INHALER WITH SPACER AND DRY POWDER INHALER FOR DELIVERY OF SALBUTAMOL IN ACUTE EXACERBATIONS OF BRONCHIAL ASTHMA
}

Objective: To compare the efficacy of metered dose inhaler with spacer with dry powder inhaler for delivery of salbutamol in acute exacerbation of bronchial asthma Design: Randomized controlled trial in the Setting of Department of Pediatrics, Patna Medical College and Hospital Patna Methods: Children in the age group of 5 - 12 years who presented with a mild or moderate acute exacerbation of asthma were randomized to receive $400 \mathrm{mcg}$ salbutamol by either a MDI with spacer or a DPI. The changes in the wheezing and accessory muscle scores, SaO2, and PEFR were recorded and subjected to statistical tests for significance. Results: Two hundred and fifty-three children were studied; 128 were assigned to the MDI-spacer group and 125 to rotahaler (DPI) group. After receiving treatment, the PEFR improved by about $11 \%$ in both the groups. The oxygen saturation increased by $2 \%$ in both the groups. Within each group, the improvement in PETR, SaO2, wheeze and accessory muscle score after the treatment was statistically significant. Conclusion: Metered dose inhaler with spacer and dry powder inhaler are equally effective in delivering salbutamol in therapy of mild to moderate acute exacerbations of bronchial asthma in children between 5-12 years of age.

\section{INTRODUCTION}

ASTHMA is a chronic inflammatory condition of the Jung airways resulting in episodic airflow obstruction i.e. AIRWAY HYPER RESPONSIVENESS to variety of agents. Aerosol inhalation has long been recognized as one of the main modalities of treatment of asthma. Studies comparing the clinical efficacy of MDI and DPI in the treatment of asthma in children are limited especially so about comparison in acute exacerbations. Therefore, we conducted a study to compare the response to salbutamol inhalation delivered by metered dose inhaler with a spacer versus rotahaler (a DPI) in children presenting with mild or moderate acute exacerbation of asthma.

\section{SUBJECTS AND METHODS}

The study was conducted in the Department of Pediatrics, Patna Medical College \& Hospital Patna, Bihar, from July 2019 to June 2020. The study subjects were children in the age group of 5-12 years who presented with a mild or moderate acute exacerbation of asthma. Mild exacerbation was defined as presence of cough, moderate wheeze i.e. found only at the end of expiration), breathlessness while walking, talks in sentences, has increased respiratory rate, with PEFR $70 \%$ of predicted ... absence of cyanosis, Moderate exacerbation was defined as loud wheeze lie. present throughout exhalation), breathlessness while at rest, talks in phrases, has increased respiratory rate, with PEFR $-40-69 \%$ or predicted ... absence of cyanosis.

Children with features of severe acute exacerbation or lEFR less than $40 \%$ of the predicted value or a lower respiratory tract infection were excluded. In addition, children who had received a bronchodilator within the last 6 hours of presentation were excluded.

The children were then randomized by using a random number table to receive salbutamol by either a MDI with spacer or aDPI. Children were examined to record the wheezing and accessory muscle scores, oxygen saturation $\left(\mathrm{SaO}_{2}\right)$ and PEFR using Wright's mini peak flow meter, Children were then administered $400 \mathrm{mcg}$ of salbutamol by either a MOI with spacer or a DPI (Rotahaler). Children assigned to the MDI group received four $100 \mathrm{mcg}$ puffs of salbutamol using a $750 \mathrm{~mL}$ commercially available spacer with valve (TRANS SPACER, Lupin). It was ensured that each puff was administered with regular breathing for about $30 \mathrm{sec}$ or 5-10 breaths and a tight seal was maintained, Children assigned to rotahaler (Cipla Ltd., Mumbai, India) group received 2 rotacaps (Cipla Lid., Mumbai, India) each of 200 mcg salbutamol. Children performed 5 maximum inspiratory maneuvers after each dose. Thirty-minute after treatment, the children were reevaluated. Baseline parameters were compared for the two qroups.

\begin{tabular}{l} 
T'TABLE I-Baseline Characteristics of study population \\
\begin{tabular}{|l|l|l|l|}
\hline Parameter & $\begin{array}{c}\text { MDI- spacer group } \\
(\mathrm{n}=128)\end{array}$ & $\begin{array}{c}\text { Rotahaler group } \\
(\mathrm{n}=125)\end{array}$ & P value \\
\hline Male:Female & $80: 48$ & $65: 60$ & 0.03 \\
\hline Age in Years* & $9(8-10)$ & $10(9-11)$ & 0.29 \\
\hline PEFR (liters/min) & $190(170-210)$ & $199(170-207)$ & 0.70 \\
\hline Percent predicted PEFR* & $77.5 \%(73-83.9)$ & $74.25 \% 71-78.1)$ & 0.17 \\
\hline $\mathrm{SaO}_{2}(\%)$ & $96(95-96)$ & $96(95-96)$ & 0.77 \\
\hline Wheeze score* & $2(1-2)$ & $1(1-2)$ & 0.18 \\
\hline Accessory muscle score* & $1(0-1)$ & $0(0-1)$ & 0.04 \\
\hline "median (95\% confidence interval). & & &
\end{tabular} \\
\hline
\end{tabular}

The changes in the wheezing and accessory muscle scores, Sao, and PEFR were recorded and subjected to statistical tests for significance.

\section{RESULTS}

Two hundred and fifty-three children were studied, 128 children were assigned to the MDI-spacer group and 125 to Rotahaler group. The baseline characteristics are shown in Table 1. The proportion of boys was significantly more in the MDI-spacer group. Percent predicted PEFR in both the groups were similar. Children in the MDI-spacer group had a higher accessory muscle use score.

After receiving treatment, the PEFR improved by about $11 \%$ in each of the groups (Table 1). The oxygen saturation increased by $20 \%$ in both the groups. The accessory muscle Live scores were significantly less in the rotahaler group: However, the wheeze scores were comparable. Within each group, the improvement in $\mathrm{PEFR}, \mathrm{SaO}_{2}$, wheeze and accessory muscle score after the treatment were statistically significant. In both the groups the children cooperated equally well.

\section{DISCUSSION}

Delivery of drugs as aerosols, particularly via metered dose inhalers, has been a major breakthrough in the treatment of asthma, as it allows adequate drug deposition in the lower respiratory tract. However, despite adequate counselling many patients are unable to use a pressurized inhaler efficiently, especially children. Failure to Co-ordinate inhaleractuation with inspiration is the most important drawback. The use of a spacer device eliminates the need for any breath- hand co-ordination. But the side-effects of propellants and lubricants are not eliminated. 
TABLE II-Post-treatment Characteristics in the two Groups

\begin{tabular}{|l|l|l|l|}
\hline Parameter & $\begin{array}{l}\text { MDI-spacer group } \\
(\mathrm{n}=128)\end{array}$ & $\begin{array}{l}\text { Rotahaler } \\
\text { group } \\
(\mathrm{n}=125)\end{array}$ & P value \\
\hline PEFR (Liters/min) * & $\begin{array}{l}207.5(189.2- \\
237.4)\end{array}$ & $\begin{array}{l}201(191.9- \\
244.1)\end{array}$ & 0.11 \\
\hline Percent predicted PEFR* & $87.7(81.8-92.2)$ & $\begin{array}{l}83.3(77.9- \\
86.4)\end{array}$ & 0.09 \\
\hline $\begin{array}{l}\text { \% increase in PEFR* after } \\
\text { treatment* }\end{array}$ & $11.2(9.3-13.3)$ & $11.1(8.1-12.5)$ & 0.63 \\
\hline SaO $_{2}(\%)^{*}$ & $97(97-97)$ & $98(97-98)$ & 0.09 \\
\hline $\begin{array}{l}\text { Increase in } \mathrm{SaO}_{2}(\%) \text { after } \\
\text { treatment* }\end{array}$ & $2.06(1.04-2.08)$ & $2.08(1.05-2.1)$ & 0.13 \\
\hline Wheeze score* $^{*}$ & $1(0-1)$ & $1(0-1)$ & 0.14 \\
\hline Accessory muscle score* & \multicolumn{1}{|c|}{$(0-0)$} & $0(0-0)$ & 0.02 \\
\hline
\end{tabular}

Dry powder inhalers (DPIs) provide an alternative formulation for drug delivery to the airways without the attendant problems of MDls and are bioequivalent to them.

There is no need for any breath-hand actuation. But the need for a minimum level of inspiratory flow for a DPI to be useful still exists.

We observed that efficacy of salbutamol in mild or moderate acute exacerbation of asthma was similar when the drug is delivered by MDI-spacer or a dry powder inhaler. The increase in PEFR in the two groups was approx. $11 \%$. We used PEFR values predicted for height to calculate the decrease in PEFR. Accessory muscle scores were higher in MDI group than Rotahaler group at baseline, while other parameters to assess severity were comparable. There was significant improvement in the scores in both the groups; however, the difference between two groups persisted. This discrepancy may be avoided by use of composite scores for assessment of security.

A number of studies have been done to compare the efficacy of the many inhalational systems available among adults. Most of them have shown that salbutamol administered a DPI is as efficacious as that by MDI.

There are very few studies to show the clinical efficacy of rotahaler in children with acute exacerbations of asthma. Ina study on 44 children, Bronksy, et al. observed that the two devices (rotahaler and MDI) were equally efficacious in delivering salbutamol in exercise- induced asthma. Alwarez, et al, in an analysis of 10RCTs observed that in stable asthma in children, salbutamol administered via MDIs is as effective as DPIs. No additional clinical benefit was found in either case. Singh and Kumar compared the clinical efficacy of a transparent, DPI (transparent Rotahaler) with MDI and spacer in moderate persistent childhood asthma. The two groups of children received both. inhaled steroids and bronchodilators through either of the devices for 6 weeks and then were crossed over to the other group. Comparisons made on weekly.

symptom scores, PEFR at interval visits, PEF variability, additional bronchodilator use are acute exacerbations of asthma did not reveal any statistically significant differences during the two treatment periods. We studied the efficacy of the two devices in only acute exacerbations and only for bronchodilators. Based on our findings and review of literatures, we conclude that meters dose inhaler with spacer and dry powder inhaler have equal efficacy in therapy of acute exacerbation of bronchial asthma in children,

\section{REFERENCES}

1. Afshar R, Medoff BD, Luster AD: Allers asthma: a tale of many T cells. Clin Everything Allergy 2008;38:1847-1857.

2. Akdis CA, Akdis M: Mechanisms zem treatment of allergic disease in the bar picture of regulatory T cells.J Allers Clinlmmunol 2009; 123:735-746.

3. Bentur L, Canny GJ, Shields.MD, Kerepar,E; Schuh S, Reisman JJ, et al.Controls trial of nebulized albuterol in chilmes younger than 2years of age with a contest asthma. Pediatrics 1992;89::133-137.

4. Bieber T: Atopic dermatitis.N Engl J Med 2008;358:1483-1494.

5. Boyce JA, Broide D, Matsumoto K, et al: Advances in mechanisms of asthma, allergy, and immunology in 2008.J Allergy Clin Immunol 2009; 123:569-574

6. Bronksy EA, Spector SL, Pearlman DS, JustusSE, Bishop AL. Albuterol aerosol versus rotacaps in exercise-induced bronchospasm. JAsthma 1995; 32: 207 -
214.

7. Callaghan C, Barry P. Spacer devices in the treatment of asthma. BMJ 1997; 314:1061-1062.

8. Chen SH, Yin TJ, Huang JL. An exploration of the skills needed for inhalation therapy in schoolchildren with asthma in Taiwan. Ann Allergy Asthma Immunol 2002; 89:311-315. St. Gemeill, NinaF. Schor, Richard

9. Golish J, Curtis-McCarthy P, McCarthy E.Behrman, 190, 2011, 780-801. K, Kavuru M, Wagner W, Beck G, et al. 13. Singh M, Kumar L. Randomized Albuterol delivered by MDI, MDI + spacer, comparison of a dry powder inhaler and and rotahaler device. A comparison of metered dose inhaler with spacer in efficacy and safety. JAsthma 1998;35: management of children with asthma.373-379. Indian Pediatr 2001;38:24-28.

10. Hindle M, Newton DAG, Chrystyn H. Dry 14. Tukainen H, Terho EO. Comparison of powder inhalers are bioequivalent to inhaled salbutamol powder and aerosol MDls. Chest 1995; 107:629-633

11. Negro Alwarez JM, Miralles Lopez JC, felix Toledo R, Pagan Aleman JA, Garcia Selles FJ, Lopez sachez JD, et al. pMDIs versus DPIsto rapid-acting b2 agonists for asthma in children. Allergol Immunopathol 2002;20:245-249.

12. Nelson textbook of paediatrics, Robert M. Kliegman, BonitaF. Stantion, JosephW. St Genelll, MinaF, NinaF, Schor, Richard E.Behrman, 19e,2011,780801.

13. Singh M, kumar L. Randomized comparison of a dry powder inhaler and metered dose inhaler with spacer in management of children with asthma Indian pediatr $2001 ; 38 ; 24-28$.

14. Tukainen H, Terho EO. Comparison of inhaled salbutamol powder and aerosol in asthmatic patients with low peak in asthmatic patients with low peak expiratory flow level.Eur J Clin Pharmacol 1985;27;645-647.

15. Warner JO Naspitz CK. Third International pediatric consensus statement on the Management of childhood Asthma. International pediatric Asthma consensus Group. pediatr pulmonal 1998; 1-17. 